\title{
Changes in Oxygen Saturation and Walk in Relation to Smoking and Types of Shoes
}

\author{
Jea-Cheol Park', Jong-Man Han², Woon-Soo Cho ${ }^{3}$, Yong-Nam Kim³
}

'Department of Physical Therapy, Graduate School, Nambu University, Gwangju; ${ }^{2}$ Department of Physical Therapy, Chunnam Techno College, Gwangju; ${ }^{3}$ Department of Physical Therapy, Nambu University, Gwangju, Korea

Purpose: The purpose of this study is to examine the effects of types of shoes and distance travelled on oxygen saturation and walk in relation to smoking.

Methods: To achieve this goal, the researcher divided 20 normal male adults into two groups: a smoking group (10) and a non-smoking group (10) and used a treadmill to have them walk in intervals of 3 days, a total of 4 times.

Results: By analyzing their walk, the following results were obtained: oxygen saturation showed statistically significant results in both the smoking group and the non-smoking group. The smoking group showed significant results for left pace and significant results were achieved for setting foot and shaking in both the smoking group and the non-smoking group. In comparison of oxygen saturation between groups, there were significant results for $3 \mathrm{~km}$ sneakers walk and $3 \mathrm{~km}$ slippers walk. There were significant results for width in $3 \mathrm{~km}$ sneakers walk, left and right pace in $3 \mathrm{~km}$ slippers walk, and setting foot in $1 \mathrm{~km}$ sneakers walk.

Conclusion: In conclusion, in the smoking group changes in walk occur if the shoes are more unstable and the distance travelled becomes longer.

Keywords: Oxygen Saturation, Smoking, Walk, Shoes

\section{서 론}

흡연 시 발생하는 니코틴은 심박수 증가, 혈관수축, 혈압상승 등의 문 제를 일으켜 혈액순환에 지장을 초래하며, 관상동맥과 같은 심혈관 질환을 유도한다.1 담배 연기 중 일산화탄소는 산소보다 헤모글로빈 과의 결합력이 250 배나 강하여 혈액 중의 헤모글로빈과 결합하여 동 맥혈의 산소포화도를 낮추고 산소해리곡선을 왼쪽으로 이동시켜 동 일 조건에서 산소의 이용 능력을 떨어뜨리며, 타르는 기도의 점액을 자극하고 기관지 수축을 유도하여 기도저항을 증가시켜 폐 기능을 감소시키고 심폐기능을 저해하여 운동수행능력을 감소시킨다. ${ }^{2}$ 이처 럼 흡연은 운동에 필요한 산소 운반을 방해하고 운동수행능력을 감 소시켜 일상생활에 영향을 미치고 있다.

한편, 보행은 태어나면서부터 오랜 기간에 걸쳐 신경계, 근육계, 생 체 역학적 그리고 운동 기능학적 변화의 과정에서 이루어진 지극히 복잡한 운동 패턴을 말하며, ${ }^{3}$ 하지의 부하와 비 부하 주기의 특성을 나타내는 임의의 이동방법으로 인체가 두 발 보행을 통해 하나의 지
점으로부터 다른 지점으로 이동하는 것이라고 하였다. ${ }^{4}$ 이러한 보행 은 대표적인 유산소운동으로 혈액순환을 촉진하여 심혈관계 질환 을 예방하고, 체지방을 감소시키며 각종 성인 질병 예방에 효과적인 운동 중 하나로 최근주목을 받고 있다.

보행을 위한 발의 역할은 체간 이동에 필요한 추진력과 진행방향 을 제공하며, 체중을 지지하고 지면에 대한 적응 및 신체의 중심이동 에 반등하여 균형을 유지하는 역할을 한다. ${ }^{5} \mathrm{Nigg}^{6}$ 에 의하면 신발은 인간의 보행에 있어 중요한 부분이라 하였는데, 맨발 보행 시 체중의 1-2배, 보행 시 2-3배의 충격을 받고, 신발을 착용하면 발로 전해지는 충격을 흡수하고 발을 포함한 모든 관절을 보호하고 부상과 상해예 방의 역할을 하며, 자신의 발에 적합하지 않은 신발을 장시간 착용하 는 것은 발의 변형을 유발한다. 이러한 발 변형은 여러 가지 문제점 을 발생시키며, 신체 분절이 서로 고리와 같이 연결되어 있어서 자연 스럽게 발목, 무릎, 골반, 허리, 어깨 그리고 목까지 통증을 동반하는 다양한 이상 증세로 이어지기 때문에 이상 보행장애가 발생하여 보 행에 영향을 미치게 된다. 이렇듯 신발은 단순히 발 보호 목적이 아니 
라 보행 또는 일의 능률 증진, 그리고 현대에 들어서 인간의 건강에 많은 영향을 미치는 도구로써 사용되고 있다.9

이에 본 연구는 흡연이 심폐기능을 저하시키고 산소운반 능력을 감소시키므로 에너지효율 체계에 문제를 발생시켜 몸의 한 부분인 근.골격계의 이상을 일으킬 수 있고 보행에 영향을 줄 수 있다는 가 정하에 실험을 진행하였다.

최신 선행연구를 살펴보면 $\mathrm{Hong}$ 과 $\mathrm{Kim}^{10}$ 은 흡연 여부와 자세변화 에 따른 폐 기능 변화 연구에서 흡연군이 비 흡연군보다 폐 환기 기능 이 더 감소한다고 보고하였고, Chang과 Lee ${ }^{11}$ 는 하이힐 보행이 무릎 관절 회전력을 증가시켜 퇴행성 변화와 연관성이 있다고 보고하였으 며, $\mathrm{Ryu}^{12}$ 는 하이힐 보행은 안정성을 유지하기 위해 근 활동량이 증대 된다고 보고하였다. Kim과 Park ${ }^{13}$ 은 신발 굽 높이에 따른 일어서기 동 작 시 하지 관절의 각도를 측정하여 높은 굽 착용 후 일어서기 할 때 관절에서 과도한 힘이 발생하여 통증 유발과 동작 수행 동안 안정성 및 관절 상해 위험성을 제시하였다. 또한, 성인들 대상으로 연령별 보 행에서 운동형상학적, 운동역학적 분석을 실시한 연구가 보고 되었 으며, ${ }^{14}$ 슬리퍼 착용 보행 관련 연구도 보고되고 있다. $\operatorname{Kim}^{15}$ 은 9명의 중학생을 대상으로 슬리퍼를 착용하고 걷기 및 달리기 시 발바닥 굽 힘과 뒤 발부의 가쪽 번짐, 아킬레스힘줄 각의 엎침 운동이 발생하여 불안정한 보행자세와 부상을 유발한다고 하였다. 각 신발 보행에 대 한 선행연구들은 많이 보고되었지만 흡연 여부에 따른 신발유형, 보 행 거리 간의 차이가 산소포화도와 보행변화에 어떠한 영향이 미치 는지에 대한 연구는 아직 부족한 실정이다. 따라서 본 연구는 트레드 밀을 이용해 흡연이 산소포화도와 보행변화에 어떤 영향을 미치는 지를 알아보고 보행 변화와 금연 관련 캠페인의 기초자료를 제시하 고자한다.

\section{연구방법}

\section{1. 연구대상}

본 연구에 참여한 대상자는 남자 20 명으로 1 년 이상 하루 한 갑씩 흡 연한 흡연군 10 명과 1 년 이상 흡연을 하지 않은 비 흡연군 10 명으로 나누어 실험을 진행하였으며, 각 실험 대상자들은 연구에 참여를 동 의한 자와 내·외과적 질환 및 근.골격계 질환이 없는 자, 6 개월 이상 정기적으로 운동하지 않는 자, 보행에서 이상 보행이 발생하지 않는 자로 무작위 선정하였으며 2013년 10월 29일부터 4개월간 시행하였 으며 연구대상자의 일반적 특성은 Table 1 과같다.

\section{2. 실험방법}

본 연구는 흡연군과 비 흡연군으로 나눈 후 군마다 신발 착용 전 산 소포화도와 보행 변화를 사전 측정하였고, 슬리퍼를 신고 $1 \mathrm{~km}$ 보행
Table 1.General characteristics of subjects

\begin{tabular}{lccc}
\hline & Smoking $(\mathrm{N}=10)$ & Non-Smoking $(\mathrm{N}=10)$ & $\mathrm{p}$ \\
\hline Age (year) & $20.9 \pm .99$ & $21.9 \pm .73$ & 0.093 \\
Height $(\mathrm{cm})$ & $172.1 \pm 3.21$ & $174.1 \pm 5.85$ & 0.701 \\
Weight $(\mathrm{kg})$ & $67.3 \pm 11.80$ & $68.2 \pm 12.20$ & 0.943 \\
BMl $\left(\mathrm{kg} / \mathrm{m}^{2}\right)$ & $22.6 \pm 3.23$ & $22.6 \pm 4.40$ & 0.804 \\
\hline
\end{tabular}

Values are presented as mean \pm standard deviation.

BMI, body mass index.

후 보행분석과 산소포화도 측정을 하였다. 측정 후 1 시간 정도의 충 분한 휴식을 취한 후, 슬리퍼를 신고 $3 \mathrm{~km}$ 보행을 시행하였으며, 3 일 후 슬리퍼 보행과 같은 동일 방법으로 운동화 보행분석과 산소포화 도 측정을 하였다. 각 신발의 보행분석 후 3 일간의 휴식기간을 준 뒤 운동화 착용과 슬리퍼 착용 순서를 바꾸어 같은 방법으로 4 주간 총 4 회를 측정하여 평균값을 구했다.

\section{1) 측정도구 \\ (1) 보행측정}

보행분석을 위해 트레드밀(FDM-T system. zebris medical GMBH Germany)을 이용하였고 정면에 응시 기준점을 만들어 실험자 모두 동일 하게 시선을 맞추었으며, 출발점 바닥면도 표시를 하여 출발지점을 동일하게 하여 측정하였고, 5 분간 준비운동을 시행한 후 실험을 시 행하였다. 트레드밀의 경사도는 수평( $0 \%)$ 으로 설정하였고, 속도는 일 반적 걸음걸이인 $4 \mathrm{~km} / \mathrm{h}$ 로 설정하여 각 1 분간 보행 패턴을 측정하였 다. 보행분석에 사용된 트레드밀은 보행분석이 가능한 발판 센서가 $112 \mathrm{~cm} \times 49 \mathrm{~cm}$ 에 정확성 및 내구성이 높은 콘덴서 방식의 센서가 3,432 개 내장되어 있으며, 샘플링 비율(sampling rate)은 $100 \mathrm{~Hz}$ 빠른 표본 주파수를 사용하였고 측정된 자료는 WINFDM-T program을 통해수집하였다.

\section{(2) 산소포화도 측정}

산소포화도 측정을 위해 산소포화도 측정기(rossmax SA210, USA)를 이용하였고 피검자는 보행 후 손가락에 센서를 부착하여 디지털 상 나오는 수치를 이용하였다. 산소포화도 측정기기는 비침습적인 방법 으로 손가락의 세동맥상에 맥박 산소계측기에서 나오는 광전용적맥 파(photoplethysmograph, $\mathrm{PPG}$ )를 이용하며, 파장이 $940 \mathrm{~nm}$ 인 적외선 광(infrared light, IR)과 $660 \mathrm{~nm}$ 의 적색광(red light, RED)으로부터 측정 한 신호를 이용하여 산소포화도(saturation of peripheral oxygen, SpO2) 를 측정할 수 있고, 산소포화도의 의미는 전체 혈색소의 양에 대한 산소혈색소 양의 백분율로 나타낸다.16

\section{(3) 분석방법}

모든 자료는 SPSS ver 12.0 통계 프로그램을 이용하여 분석하였고 대 
상자의 일반적 특성의 정규분포 여부를 알아보기 위해 단일표본 Kolmogorov-smirnov 검정을 하여 정규분포가 인정되어 각각의 측정 항목에서 시기에 따른 차이를 알아보기 위해 일원배치분산분석(one way ANOVA)을 하였고, 사후검정은 Scheffe의 다중비교분석을 실시 하였다. 각 군의 교호작용 차이를 알아보기 위해 독립표본 t-검정(independent t-test)을 실시하였으며 통계학적 유의성을 검증하기 위해 유의수준을 0.05 로 하였다.

\section{결 과}

\section{1. 산소포화도(oxygen saturation)의 변화}

산소포화도 변화의 경우 흡연 여부와 보행변화에 따라 산소포화도 변화는 흡연군과 비 흡연군에서 유의한 차이가 있었다 $(\mathrm{p}<0.01)$. 사후 검정 결과 흡연군은 맨발과 $1 \mathrm{~km}$ 운동화 보행, 맨발과 $1 \mathrm{~km}$ 슬리퍼 보 행, 맨발과 $3 \mathrm{~km}$ 운동화 보행에서 유의한 차이가 있었고( $\mathrm{p}<0.05)$, 비 흡연군 변화의 경우 맨발과 $3 \mathrm{~km}$ 운동화 보행, 맨발과 $3 \mathrm{~km}$ 슬리퍼 보 행에서 유의한 차이가 있었다 $(\mathrm{p}<0.05)$. 두 군 간의 차이에서는 $3 \mathrm{~km}$ 운동화와 $3 \mathrm{~km}$ 슬리퍼 보행에서 흡연 여부에 따라 유의한 차이가 있 었다 $(\mathrm{p}<0.05)($ Table 2$)$.

\section{2. 양발 너비(step width)의 변화}

양발 너비 변화의 경우 흡연 여부와 보행 변화에 따라 너비의 변화는
유의한 차이가 없었다 $(\mathrm{p}>0.05)$. 두 군 간의 차이에서는 $3 \mathrm{~km}$ 운동화 보행에서 흡연 여부에 따라 유의한 차이가 있었다 $(\mathrm{p}<0.05)$ (Table 2).

\section{3. 왼 보장(left foot step length)의 변화}

왼 보장 변화의 경우 흡연 여부와 보행변화에 따라 흡연군에서 유의 한 차이가 있었다 $(\mathrm{p}<0.05)$. 사후검정결과 흡연군은 맨발과 $3 \mathrm{~km}$ 운동 화 보행에서 유의한 차이가 있었고 $(\mathrm{p}<0.05)$, 비 흡연군 변화의 경우 유의한 차이가 없었다 $(\mathrm{p}>0.05)$. 두 군 간의 차이에서는 $3 \mathrm{~km}$ 슬리퍼 보행에서 흡연 여부에 따라 유의한 차이가 있었다 $(\mathrm{p}<0.05)$ (Table 2).

\section{4. 오른 보장(right foot step length)의 변화}

오른 보장 변화의 경우 흡연 여부와 보행 변화에 따른 유의한 차이가 없었다 $(\mathrm{p}>0.05)$. 두 군 간의 차이에서는 $3 \mathrm{~km}$ 슬리퍼 보행에서 흡연 여부에 따라 유의한 차이가 있었다 $(\mathrm{p}<0.05)($ Table 2).

\section{5. 디딤기(stance phase)의 변화}

디딤기 변화의 경우 흡연 여부와 보행변화에 따라 흡연군과 비 흡연 군에서 유의한 차이가 있었다 $(\mathrm{p}<0.01)$. 사후검정 결과 흡연군은 맨발 과 $1 \mathrm{~km}$ 운동화 보행, 맨발과 $1 \mathrm{~km}$ 슬리퍼 보행, 맨발과 $3 \mathrm{~km}$ 운동화 보행에서 유의한 차이가 있었고 $(\mathrm{p}<0.05)$, 비 흡연군은 맨발과 $1 \mathrm{~km}$ 슬 리퍼 보행, 맨발과 $3 \mathrm{~km}$ 슬리퍼 보행에서 유의한 차이가 있었다 $(\mathrm{p}<0.05)$. 두 군 간의 차이에서는 $1 \mathrm{~km}$ 운동화 보행에서 흡연 여부에

Table 2. Oxygen saturation and walk variation

\begin{tabular}{|c|c|c|c|c|c|c|c|c|c|}
\hline & & a & $b$ & $C$ & $d$ & e & $\mathrm{F}$ & $\mathrm{p}^{*}$ & Post-hoc \\
\hline \multirow[t]{2}{*}{ OS } & Smoking & $99.80 \pm .42$ & $98.30 \pm .94$ & $98.40 \pm .51$ & $98.60 \pm .69$ & $98.80 \pm 1.03$ & 6.241 & $0.00^{\$}$ & $a>b, c, d$ \\
\hline & Non-smoking & $99.40 \pm .69$ & $98.50 \pm .70$ & $98.60 \pm .69$ & $97.50 \pm .97$ & $97.70 \pm .82$ & 9.403 & $0.00^{\S}$ & $a>d, e$ \\
\hline Group & $\mathrm{p}^{+}$ & 0.14 & 0.60 & 0.48 & $0.01^{\S}$ & $0.02^{\ddagger}$ & & & \\
\hline \multirow[t]{2}{*}{ SW } & Smoking & $9.90 \pm 3.24$ & $8.45 \pm 3.11$ & $9.75 \pm 2.54$ & $7.56 \pm 2.30$ & $9.85 \pm 1.91$ & 1.548 & 0.20 & $a, b, c, d, e$ \\
\hline & Non-smoking & $10.0 \pm 2.65$ & $10.35 \pm 3.41$ & $9.85 \pm 3.01$ & $10.3 \pm 2.97$ & $9.75 \pm 3.46$ & .073 & 0.99 & $a, b, c, d, e$ \\
\hline Group & $\mathrm{p}^{+}$ & 0.94 & 0.21 & 0.94 & $0.03^{+}$ & 0.94 & & & \\
\hline \multirow[t]{2}{*}{ LSL } & Smoking & $80.69 \pm 2.57$ & $83.89 \pm 1.81$ & $83.04 \pm 3.18$ & $84.94 \pm 3.83$ & $82.29 \pm 2.52$ & 3.197 & $0.02^{\ddagger}$ & $d>a$ \\
\hline & Non-smoking & $82.31 \pm 3.45$ & $83.76 \pm 4.45$ & $86.21 \pm 4.11$ & $84.29 \pm 4.10$ & $85.57 \pm 3.58$ & 1.470 & 0.21 & $a, b, c, d, e$ \\
\hline Group & $\mathrm{p}^{+}$ & 0.23 & 0.95 & 0.07 & 0.72 & $0.03^{\ddagger}$ & & & \\
\hline \multirow[t]{2}{*}{ RSL } & Smoking & $81.55 \pm 2.67$ & $84.15 \pm 2.96$ & $83.30 \pm 3.11$ & $84.30 \pm 2.67$ & $82.50 \pm 2.46$ & 1.715 & 0.16 & $a, b, c, d, e$ \\
\hline & Non-smoking & $83.31 \pm 2.99$ & $85.28 \pm 3.07$ & $85.51 \pm 3.68$ & $84.44 \pm 3.01$ & $85.46 \pm 2.77$ & .903 & 0.47 & $a, b, c, d, e$ \\
\hline Group & $\mathrm{p}^{+}$ & 0.17 & 0.41 & 0.17 & 0.91 & $0.02^{\neq}$ & & & \\
\hline \multirow[t]{2}{*}{ Stance phase } & Smoking & $60.33 \pm 1.39$ & $62.64 \pm 1.16$ & $62.17 \pm .45$ & $62.74 \pm .72$ & $61.86 \pm 1.50$ & 7.542 & $0.00^{\S}$ & $b, c, d>a$ \\
\hline & Non-smoking & $59.74 \pm 1.78$ & $61.13 \pm 1.28$ & $62.80 \pm 1.51$ & $60.90 \pm 3.11$ & $62.75 \pm 1.80$ & 4.263 & $0.01^{\S}$ & $c, e>a$ \\
\hline Group & $\mathrm{p}^{+}$ & 0.43 & $0.02^{\ddagger}$ & 0.23 & 0.10 & 0.25 & & & \\
\hline \multirow[t]{2}{*}{ Swing phase } & Smoking & $39.18 \pm 1.44$ & $37.02 \pm 1.29$ & $37.11 \pm .88$ & $37.09 \pm .75$ & $37.64 \pm 1.90$ & 4.753 & $0.01^{\S}$ & $a>b, c, d$ \\
\hline & Non-smoking & $42.44 \pm 9.66$ & $37.98 \pm 1.31$ & $36.67 \pm 1.09$ & $38.55 \pm 2.81$ & $35.15 \pm 5.36$ & 2.796 & $0.03^{\ddagger}$ & $a, b, c, d, e$ \\
\hline Group & $\mathrm{p}^{+}$ & 0.31 & 0.12 & 0.33 & 0.15 & 0.18 & & & \\
\hline
\end{tabular}

a: barefoot b: 1 km Sneakers c: 1 km Slipper d: 3 km Sneakers e: 3 km Slipper. 
따라 유의한차이가 있었다 $(\mathrm{p}<0.05)$ (Table 2).

\section{6. 흔들기(swing phase)의 변화}

흔들기 변화의 경우 흡연 여부와 보행변화에 따라 흡연군과 비 흡연 군에서 유의한 차이가 있었다 $(\mathrm{p}<0.05)$. 사후검정결과 흡연군은 맨발 과 $1 \mathrm{~km}$ 운동화 보행, 맨발과 $1 \mathrm{~km}$ 슬리퍼 보행, 맨발과 $3 \mathrm{~km}$ 운동화 보행에서 유의한 차이가 있었고 $(\mathrm{p}<0.05)$, 비 흡연군은 유의한 차이가 없었다 $(\mathrm{p}>0.05)$. 두 군 간의 차이에서는 유의한 차이가 없었다 ( $>0.05)$ (Table 2).

\section{고 찰}

흡연은 심혈관계 반응을 증가시키고 폐 기능의 저하를 일으켜 최대 하 운동과 최대운동수행능력을 저하한다고 알려져 왔다.17-19 흡연으 로 인해 폐 기능 저하, 탄소화 헤모글로빈의 증가, 운동 시 심박수 증 가, 최대 산소 섭취량의 감소 등이 초래되어 운동하는 동안 근 수행능 력이나 지구력을 감소시키며, ${ }^{20}$ 이러한 운동능력 저하는 보행에 필요 한 운동 수행능력을 저하시켜 보행에 영향을 미치게 된다. 흡연과 지 구력의 상관관계에 대한 선행연구 ${ }^{21}$ 들이 있는데, Conway와 Cronan ${ }^{22}$ 은 미 해군 3,045 명을 대상으로 한 연구에서 $2.4 \mathrm{~km}$ 심폐지구력 검사 를 시행한 결과 흡연을 하는 사람들의 달리기 속도가 비흡연자들보 다 유의하게 느렸다고 하였다. 유산소 운동능력의 지표인 최대산소 섭취량은 대부분 연령대에서 비흡연자가 흡연자보다 더 높은 수치를 나타내고 있다고 하였다. ${ }^{23,24,17}$ 최대 산소 섭취량이 증가할수록 유산 소운동능력 또한 증가한다고 할 수 있다.

이에 본 연구에서 흡연과 신발유형과 거리에 따른 산소포화도와 보행 변화를 연구하였다. 산소포화도는 흡연군과 비 흡연군에서 유 의한 차이가 있었고( $\mathrm{p}<0.01)$, 흡연군에서 맨발 보행, $3 \mathrm{~km}$ 슬리퍼, 3 $\mathrm{km}$ 운동화, $1 \mathrm{~km}$ 슬리퍼, $1 \mathrm{~km}$ 운동화 순으로 감소하였고, 비 흡연군 은 맨발 보행, $1 \mathrm{~km}$ 운동화, $1 \mathrm{~km}$ 슬리퍼, $3 \mathrm{~km}$ 운동화, $3 \mathrm{~km}$ 슬리퍼 보 행 순으로 감소하였다. 군 간에서는 $3 \mathrm{~km}$ 운동화, $3 \mathrm{~km}$ 슬리퍼에서 산 소포화도 차이가 있었다 $(\mathrm{p}<0.05)$. 흡연군은 긴 보행보다, 더 짧은 보 행에서, 비 흡연군에서는 긴 보행 시 산소포화도가 감소하는 결과를 보였으며, 군 간 비교에서 비 흡연군은 $3 \mathrm{~km}$ 슬리퍼, $3 \mathrm{~km}$ 운동화 보행 시 산소포화도가 흡연군보다 줄어드는 결과를 보였는데, 이는 본 연 구 흡연자들은 1 년 이상의 습관성 흡연자들로 습관성 흡연자의 경우 저산소혈증에 적응되어있어 운동수행능력을 증가시키기 위해 말초 신경을 자극하여 신체에 산소공급을 높이려 하므로 흡연자의 헤모 글로빈 수치가 비흡연자보다 높게 나타난다고 주장한 선행연구 ${ }^{23}$ 와 일치함을 알 수 있다. 저산소혈증에 적응되면 에너지 대사 효율은 호 기성 대사에서 혐기성 대사 과정으로 변화되어 세포 생존에 필요한
삼투압을 유지함으로써 저산소혈증을 견디려는 노력으로 이와 같은 결과가 발생하였다고 생각된다. 또 다른 선행연구는 흡연 여부가 산 소포화도에 미치는 영향을 연구하여 군 간 유의하지 않는 결과를 보 였다고 보고하였는데 ${ }^{25}$ 이는 단순하게 안정한 상태에서 흡연자와 비 흡연자의 산소포화도 측정을 하였고 본 연구는 신발 유형과 보행 거 리의 변화로 인하여 위와 같은 결과가 나온 것으로 생각된다.

$\mathrm{Sato}^{26}$ 는 높은 굽을 신은 여성이 낮은 굽을 신은 여성보다 보행의 너비와 길이가 짧다고 보고하였는데, 본 연구 양발 너비의 변화에선 흡연군과 비 흡연군 보행의 변화에서 유의한 차이가 나타나지 않았 다(p>0.05). 따라서 본 연구는 굽이 없는 슬리퍼와 운동화 보행으로 구두 보행보다 지지면이 넓고 더욱 안정적인 보행으로 인해 너비의 차이는 없는 것으로 여겨지며, 군 간의 비교에서 $3 \mathrm{~km}$ 운동화 보행군 에서 유의한 차이가 있었는데 $(\mathrm{p}<0.05)$, 흡연군의 너비가 짧아진 것으 로 확인되어 흡연이 운동수행능력과 안정성에 영향을 미칠 수 있는 것으로 생각된다.

왼 보장에서는 흡연군에서 유의한 차이가 있었고 $(\mathrm{p}<0.05)$, 맨발 보 행, $3 \mathrm{~km}$ 슬리퍼, $1 \mathrm{~km}$ 슬리퍼, $1 \mathrm{~km}$ 운동화, $3 \mathrm{~km}$ 운동화 보행 순으로 길이가 길어졌으며, 비 흡연군에선 유의한 차이가 없었다 $(\mathrm{p}>0.05)$. 군 간의 차이에서는 $3 \mathrm{~km}$ 슬리퍼 보행에서 유의한 차이가 있었는데 $(\mathrm{p}<0.05), 3 \mathrm{~km}$ 슬리퍼 보행에서 흡연군이 비 흡연군보다 상대적으로 보장이 짧아졌고, $1 \mathrm{~km}$ 슬리퍼 보행도 유의하지 않지만, 비 흡연군보 다 흡연군의 왼 보장이 짧아졌다. Han 등은 정상 성인 상대로 신발유 형에 따른 보행변화에서 맨발, 슬리퍼, 운동화, 구두 보행에서 왼쪽 보 장에서 유의한 차이가 나타났고, 오른쪽 보장에서는 유의한 차이가 없었다고 보고하였고, Sherrington과 $\mathrm{Menz}^{27}$ 의 연구에 의하면 슬리퍼 와 같이 신발 뒤축이 고정되어 있지 않은 신발을 신으면 발을 질질 끄 는 보행(shuffling gait)을 하게 되고 보행 시 신발이 발과 분리되기 쉬 우며 이것은 외부의 위험 요소로 작용하여 보행의 정상적 주기를 손 상한다고 보고하였다. 이 때문에 슬리퍼 보행은 운동화 보행보다 균 형 감각이 떨어져 안정성을 증가시키고자 운동화 보행에 비해 보장 과 보폭이 짧아진 것으로 생각하며, 흡연군은 저산소혈증에 적응되 어 호기성 대사과정에서 혐기성 대사과정으로 바뀌어 체내 젖산(lactate)이 축적되면서 운동 피로를 유발하고 운동수행력을 저하해 $3 \mathrm{~km}$ 슬리퍼 왼 보장이 감소된 것으로 생각된다. 또한, 선행연구는 지지면 이 좁은구두 보행으로 인해 왼 보장 길이가 짧아진 것으로 생각되며, 본 연구는 흡연과 불안정한 슬리퍼, 보행 거리 차이 때문에 흡연군의 $3 \mathrm{~km}$ 슬리퍼 보행의 왼 보장이 감소된 것으로 생각된다.

오른 보장 변화의 경우 유의한 차이가 없었으나 $(\mathrm{p}>0.05)$, 군 간의 차이에서는 $3 \mathrm{~km}$ 슬리퍼 보행에서 유의한 차이가 있었고 $(\mathrm{p}<0.05)$, 흡 연군이 비 흡연군에 비해 보장이 상대적으로 짧아졌다. 이 또한 흡연 이 불안정하고 보행 거리가 긴 슬리퍼 보행에 영향을 미친 것으로 사 
료 된다.

디딤기와 흔들기는 보행에 있어 안정성과 관련되어 있고, 디딤기와 흔들기에 걸리는 시간을 측정함으로써 보행 안정성에 관한 정보를 얻을 수 있으며, ${ }^{28}$ 시간이 길수록 보다 안정성이 떨어져 안정성을 유 지하고자 디딤기에 걸리는 시간이 길어진다. 본 연구에서 디딤기 변 화의 경우 흡연군에서 유의한 차이가 있었고 $(\mathrm{p}<0.01)$, 맨발 보행, 3 $\mathrm{km}$ 슬리퍼, $1 \mathrm{~km}$ 슬리퍼, $1 \mathrm{~km}$ 운동화, $3 \mathrm{~km}$ 운동화, 순으로 증가하였 고, 슬리퍼 보행이 다른 보행보다 시간이 더 짧은 것으로 나타났는데 흡연과 불안정한 슬리퍼 보행으로 인해 가속보행(festinating gait) 시 나타나는 질질 그는 보행(shuffling gait)과 같은 디딤기 형태가 발생하 였다고 생각된다. 비 흡연군도 유의한 차이가 있었고 $(\mathrm{p}<0.01)$, 맨발보 행, $3 \mathrm{~km}$ 운동화, $1 \mathrm{~km}$ 운동화, $3 \mathrm{~km}$ 슬리퍼, $1 \mathrm{~km}$ 슬리퍼 순으로 뒤축 이 없는 불안정한 슬리퍼 보행이 증가하였다. 군 간 비교에서도 $1 \mathrm{~km}$ 운동화 보행에서 차이를 보였는데 $(\mathrm{p}<0.05)$, 비 흡연군보다 흡연군에 서 디딤기 시간이 증가함을 확인할 수가 있었다. $3 \mathrm{~km}$ 운동화 보행에 서도 유의하지 않았지만, 흡연군이 보다 디딤기에 걸리는 시간이 길 어진 걸로 보아 흡연이 운동화 보행에 있어 안정성에 영향을 미치게 된다는 것을 알 수 있다.

흔들기 변화의 경우 흡연군에서 유의한 차이가 있었는데 $(\mathrm{p}<0.01)$, 맨발 보행, $3 \mathrm{~km}$ 슬리퍼, $1 \mathrm{~km}$ 슬리퍼, $3 \mathrm{~km}$ 운동화, $1 \mathrm{~km}$ 운동화 보행 순으로 시간이 감소하였고, 비 흡연군도 유의한 차이가 있었다 $(\mathrm{p}<0.05)$.

비 흡연군은 맨발 보행, $3 \mathrm{~km}$ 운동화, $1 \mathrm{~km}$ 운동화, $1 \mathrm{~km}$ 슬리퍼, 3 $\mathrm{km}$ 슬리퍼 순으로 짧아졌고, 군 간의 차이에서는 유의한 차이가 없 었다(p>0.05). $\operatorname{Han}^{3}$ 은 신발 변화에 따른 보행 변화 연구에서 흔들기 변화가 차이 있었다고 보고하였고, 이는 선행연구와 일치함을 알 수 있으며 본 연구의 흡연자 군에 유의한 결과는 흡연과 슬리퍼 보행이 안정성을 감소시켰기 때문으로 생각된다. Housdorff 등 29 의 연구에 의 하면 낙상을 경험한 노인은 경험하지 않은 노인보다 디딤기에 걸리는 시간이 길고 흔들기에 걸린 시간이 짧게 나타난 것으로 보고하였는 데, 본 연구는 건강한 성인을 대상으로 실험하였고, 흡연 여부 보행 여 부 $3 \mathrm{~km}$ 보행에서 차이를 보였기 때문에 이와 같은 결과가 나온 것으 로 판단된다.

본 실험 결과 흡연군에서는 산소포화도(oxygen saturation), 왼 보장 (left foot step length), 디딤기(stance phase), 흔들기(swing phase) 4 개 패 턴에서 유의성이 나타났고, 비 흡연군은 산소포화도(oxygen saturation), 디딤기(stance phase), 흔들기(swing phase) 3 개 패턴에서 유의성이 나타났다. 산소포화도 군 간 비교에선 $3 \mathrm{~km}$ 운동화 보행과 $3 \mathrm{~km}$ 슬리 퍼 보행에서 유의성이 나타났으며, 양발 너비에선 $3 \mathrm{~km}$ 운동화 보행 에서, 왼 보장에선 $3 \mathrm{~km}$ 슬리퍼 보행에서 유의하였고, 오른 보장에선 $3 \mathrm{~km}$ 슬리퍼 보행, 디딤기는 $1 \mathrm{~km}$ 운동화 보행에서 유의성이 나타났
다. 이 결과를 놓고 보면 흡연은 신발의 안정성이 떨어지고 길이가 길 수록 보행에 영향을 주며 비흡연자보다 근피로도를 쉽게 유발해 보 행 패턴에 영향을 미치는 것으로 생각된다. 본 연구의 제한점으로는 대상자의 수가 적어 일반화하는 데 어려움이 있고, 여러 가지 속력을 이용하지 않고 $4 \mathrm{~km} / \mathrm{h}$ 속력으로 제한한 점, 실험 직전 흡연 여부를 통 제하지 않은 점 등이 있었다. 추후 이러한 제한점을 보완하여 보행 거 리의 변화와 신체특성, 신발 종류의 다변화를 조절하여 보다 더 많은 연구가 진행되어야 할 것으로 생각된다.

\section{REFERENCES}

1. Sadvik L, Erikssen G, Thanulow E. Long term effects of smoking on physical fitness and lung function: A longitudinal study of 1393 middle aged norwegian man for seven years. British MedIcal Journal. 1995; 311(7007):715-8.

2. Willemse BW, Postma DS, Timens W, et al. The impact of smoking cessation on respiratory symptoms, lung function, airway hyperresponsiveness and inflammation. Eur Respir J. 2004;23(3):464-76.

3. Han JM, Park JC, Kim HA. Gait change according to shoe styles. J Korean Health \& Fundamental Med Sci. 2013;6(3):123-8.

4. Oh TY. A study on kinematic analysis of trunk and lower extremities in stance phase of walking according to turning direction. J Kor Phys Ther. 2013;25(2):88-95.

5. Lim BI, Kim TS, Whang KS, et al. Treatment of peterson classification type VI of physeal injury in ankle joint - 2 cases report. J Korean Fract Soc. 2000;13(4):1061-6.

6. Nigg BM. Some comments for runners. In biomechanics of running shoes, N. M. nigg(ed), champaign, III: Human Kinetics Publishers. 1986: 162-5.

7. Park JE. Classification of adult women's foot shape and their morphological characteristics by age: By using 3D Foot Data of Size Korea. Graduate School of Kyung Hee University. Dissertation of Doctorate Degree. 2011.

8. Yi KO. The effects of elevated forefoot walking shoes on body composition, physical fitness, and qualitative health variables. Journal of Korean Physical Education Association for Girls and Women. 2005;19(1):9-26.

9. Kim MW. History of shoes. Seoul, Sunjin history, 2004.

10. Hong WS, Kim GW. Studies on vital capacity in a smoker. J Kor Phys Ther. 2001;13(2):347-57.

11. Chang YH, Lee WH. Influence of walking with high-heeled shoes on the knee joint of obese women. PTK. 2007;14(3):23-31.

12. Ryu JS. Effects of high-heeled Shoe with different height on the balance during standing and walking. KJSB. 2010;20(4):479-86.

13. Kim YJ, Park JW. The influence of shoes with different heels on movement of lower limb joints during sit-to-stand. J Kor Phys Ther. 2013;25(2):117-25.

14. Yoon NM, Yoon HJ, Park JS, et al. The comparative study on age-associated gait analysis in normal Korean. J Kor Phys Ther. 2010;22(2): 15-24.

15. Kim MH.The influence of types of indoor shoes on student's walking pattern according to walking and running. Graduate School of Inha University. Dissertation of Doctorate Degree. 2010. 
16. Kim TK. A Study on the measurement methode of Pulse oxymetry by using FFT (Fast Fourier Transform). Graduate School of Sangji University. Dissertation of Master's Degree. 2012.

17. Sun SK, Jung DC, Ko KJ. The effects of chronic smoking on young male adults' cardiorespiratory function. KJSS. 2006;17(2):38-46.

18. Kobayashi Y, Takeuchi T, Hosoi T, et al. Effects of habitual smoking on cardiorespiratory responses to sub-maximal exercise. J Physiol Anthropol Appl Human Sci. 2004;23(5):163-9.

19. Jatoi NA, Jerrard-Dunne P, Feely J, et al. Impact of smoking and smoking cessation on arterial stiffness and aortic wave reflection in hypertension. Hypertension. 2007;49(5):981-5.

20. Karpovich PV, Hale CJ. Tobacco smoking and physical performance. J Appl Physiol. 1951;3(10):616-21.

21. Marti B. Pekkanen J. Do joggers live longer? 3 current epidemiologic studies of the effect of physical activity on life expectancy. Schweiz Rundsch Med Prax. 1988;77(41):1097-100.

22. Conway TL, Cronan TA. Smoking, exercise, and physical fitness. Preve Med. 1992;21(6):723-34.
23. Choi DH, Choi HN.A cross-sectional study = the variability of pulmonary and lipoprotein functions in chronic smokers. January. 2000;18(1): 109-16.

24. Cha KS. A comparison of pulmonary function, aerobic power, blood pressure, blood hemoglobin in smokers and non-smokers. KAHPERD. 2001;40(3):845-57.

25. Han HJ. Effects of smoking has on vascular compliance, SpO2 and cardiopulmonary endurance. Graduate School of Kyung Hee University. Dissertation of Master's Degree. 2009.

26. Sato H, Sako H, Mukae H, et al. Gait patterns of young japaness women. J Hum Ergol. 1991;20(1):85-8.

27. Sherrington C, Menz HB. An evaluation of footwear worn at the time of fall-related hip fracture. Age Ageinq. 2003;32(3):310-4.

28. Rose J, James G. Human walking. 2nd ed. Baltimore, Williams \& Wilkins, 1994.

29. Housdorff JM, Rios DA, Edelberg HK. Gait variability and fall risk in community-living older adults: A 1-year prospective study. Arch Phys Med Rehabil. 2001;82(8):1050-6. 